\title{
Does it take too long to become a doctor?
}

\section{Part 1: Medical school and prevocational training}

\section{For this two-part series, the MJA interviewed various stakeholders about the length of medical education. This first part focuses on the pathway before vocational training.}

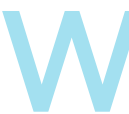

hen Dr Gavin Sandercoe watched one of the first open-heart operations on television as a young child, he knew he wanted to become a surgeon. He got straight into undergraduate medicine at the University of Sydney when he was 17 but, although he didn't take any time off from his studies, he wasn't a fully qualified surgeon until 17 years later, at age 34, in 2008.

Now Head of the Department of Plastic Surgery at Sydney's Liverpool Hospital, Dr Sandercoe says his long training path was sometimes frustrating, but it also provided him with confidence and broad skills by the time he was fully qualified.

Neither Dr Sandercoe's 17-year training path nor the fact that he was in his mid 30s when he became a fully autonomous specialist is unusual. The average age of a commencing medical student is now 22. ${ }^{1}$ The shift to graduate-entry medical schools means many students complete an undergraduate degree (at least 3 years) before commencing medicine. Then there's medical school itself (at least 4 years), internship (1 year), residency (at least 1 year) and, finally, vocational training (3-8 years). ${ }^{2}$ In addition, many doctors spend years working in the hospital system, undertaking other qualifications or doing extra research before entering specialty training.

Training times have also lengthened in recent decades. For instance, to become a general practitioner in the 1960s took a minimum of 7 years from high school. Now it takes a minimum of 10 years. ${ }^{3}$

\section{Why does it matter?}

Does it matter that the age at which doctors are fully qualified is increasing? Professor David Celermajer, Scandrett Professor of Cardiology at the University of Sydney, believes it does. He says the length of medical training is excessive and does a disservice to both the community and doctors.

"I think the community would be better served if doctors were fully autonomous as GPs or specialists in their late 20 s or early 30 s. There are two reasons for that.

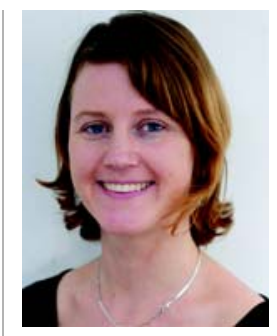

Sophie McNamara BA(Hons), GradDip(Journ), MJA News and Careers Editor

smcnamara@ mja.com.au

doi: 10.5694/mjal2.10619

\section{doi: $10.5694 / \mathrm{mia} 210619$}

\section{the earlier}

someone is able

to do a fully

autonomous

role in medicine,

the more years

of service the

community gets

from them

Perspective $p 498$ Clinical focus p 505
The first is, the earlier someone is able to do a fully autonomous role in medicine, the more years of service the community gets from them. Secondly, from the doctor's point of view, I think we all really train for the day when we can help people in an independent way. Plus, I think most doctors understand that they come out with a debt to the community and they'd like to pay that back as soon as they can and for as long as they can", he says.

Professor Celermajer adds that people are often at their most energetic and innovative before their mid 30s. "It's a time when you can contribute enormously if you're allowed to. Rather than extending the 'payback time' of medical service by increasing the retirement age, if doctors were fully autonomous by 30 instead of 35 you might get a lot more value from people", he says.

The length of medical training also has major impacts on family life, as junior doctors juggle shift work and rotations through different hospitals with family commitments or decisions about starting a family. Associate Professor Christine Jorm, coordinator of the Personal and Professional Development Theme at the Sydney Medical School, says that although there has been a shift towards more flexible arrangements, it's not always ideal.

"If the patient's still on the table bleeding, and the trainee's got to pick up the kids ... that's a problem. There is an emphasis on family-friendly hours, but the smarter emphasis would be on getting doctors through their training faster and younger", she says.

\section{Shift to graduate medical schools}

The shift from undergraduate to graduate-entry medical schools has added length to medical training, but most people who spoke to the MJA believe that having a range of options, including the new MD programs, is beneficial.

Professor Justin Beilby, President of Medical Deans Australia and New Zealand and Executive Dean of the Faculty of Health Sciences at the University of Adelaide, says: "I think the beauty of Australian medical training is that we have a real mix of medical schools with different lengths and different positioning".

Professor Celermajer believes graduate programs may produce a greater proportion of well rounded, community-oriented doctors, but says there has been a price to pay in terms of the increasingly advanced age of fully trained doctors. 


\section{Internships}

A greater cause for concern is the problem of bottlenecks in the training pathway, which many believe will worsen as the number of medical students increases.

The Australian Medical Students' Association (AMSA) is concerned that some students may even miss out on internships because of increasing student numbers. "We are now facing the possibility that the number of medical graduates may exceed the number of internships, and that may increase the training time [for those who miss out]", says AMSA Vice President Catherine Pendrey.

The increase in medical student numbers has certainly been fast and dramatic. In 2010, there were 2733 medical graduates, almost double the 1400 graduates in 1999 . Medical student numbers are predicted to continue to increase, such that in 2016 there will be 3970 graduates. ${ }^{4}$

Professor Beilby says the students' concern is valid, but a lot of work has been done to deal with this. "I'm reasonably positive that it will be resolved. Some concern remains around international students getting internships, but we have a very active process to resolve that", he says.

Recent research from the University of Melbourne and University of Queensland found that hundreds of international students could miss out on internships next year. $^{5}$

\section{Unaccredited registrars}

The bottleneck causing more concern - and which is already happening - exists before vocational training. Some doctors spend years in resident-level positions or in unaccredited "service" registrar jobs before entering vocational training.

Dr Rob Mitchell, Chair of the Australian Medical Association (AMA) Council of Doctors-In-Training, describes this situation as an "inefficiency in the system" that is likely to worsen as student numbers increase. "There are certainly trainees who spend a significant amount of time working in extended prevocational positions, or as service registrars, while waiting to get onto training programs.

"It makes no sense to have service positions - it's missing the point of expanding the number of medical students. If we have more people waiting longer to become independent practitioners, then they're not available to work in the areas where they're needed, such as rural and remote environments. It's those communities that miss out in the end."

It was this predicament that extended Dr Sandercoe's pathway to becoming a plastic surgeon. After completing his residency at Westmead Hospital, he spent 4 years as an unaccredited registrar, during which time he applied for training programs in general surgery four times and plastic surgery twice. He was accepted into plastic surgery on his second attempt. "I did 4 very painful unaccredited years and at the time I hated it. You're on the treadmill, not knowing how long it's going to take ... the entire unaccredited time was really quite demoralising and awful", he says.
He says when he went through in the early 2000s, just about everyone seeking entry into surgical training did a few years of unaccredited work. Just like unaccredited registrars going through the system now, they were denied educational opportunities offered to accredited registrars.

Despite the pain at the time, Dr Sandercoe now says the experience made him a better doctor. He gained broad surgical skills that made him more comfortable doing procedures such as abdominal reconstructions and working around high-stakes organs such as the heart.

As head of the department, he also now appreciates the value of working with junior doctors before they enter the accredited surgical program. "The unaccredited years are important to try to identify the people who should be suited to surgery, but also to identify the people who will always be awful and give them some counselling." He adds that some of the accredited trainees who come through with minimal unaccredited experience are "well and truly undercooked".

Dr John Quinn, Executive Director of Surgical Affairs at the Royal Australasian College of Surgeons (RACS), understands the frustration felt by doctors in service registrar positions, but he agrees that they are not wasted years. "It does make them more employable and trainable and they do develop more skills", he says.

Surgery is one of the most popular specialty training programs. Last year, 305 of 1082 applicants were offered a training place in one of the nine surgical specialties. ${ }^{6} \mathrm{Dr}$ Quinn says those who miss out are given prompt feedback. "Sometimes we also counsel that maybe they should think of other alternatives rather than plugging on relentlessly."

\section{Jumping through hoops}

In addition to the unaccredited years, some junior doctors who spoke to the MJA say there is an expectation that they complete extra research or qualifications to gain access to vocational training.

Dr Ross Roberts-Thomson, a postgraduate year 2 (PGY2) doctor at Royal Adelaide Hospital, recently completed a Churchill Fellowship researching prevocational training

\section{Prevocational training: the international perspective}

Churchill Fellow Dr Ross Roberts-Thomson says the biggest difference in prevocational training programs in the United Kingdom, United States and Canada compared with Australia is that those countries have no prerequisites to enter vocational training. In Canada and the US, junior doctors go straight from medical school to vocational training. "The colleges see medical graduates as 'pluripotential' doctors who have already had sufficient experience in a range of specialties", he says. Students prioritise their choice of specialty and are offered their highest matched program. In the UK, students go from medical school to a highly structured, 2-year prevocational program before entering specialty training.

His second major observation is that there are almost no "service" jobs in the UK, US and Canada. "This concept of having a doctor that isn't fully qualified, is not in a training program, but is working in a hospital - they see that as ridiculous. Inefficiency is one thing, but it's also a safety issue."

Dr Roberts-Thomson believes that Australia's training system would benefit from having a time limit on prevocational training and ensuring that doctors in unaccredited positions also had access to structured training opportunities. "That would make the system smarter, more efficient, and you'd end up with more consultants, sooner, which is what the government wants and the community needs." 
systems in the United Kingdom, United States and Canada (Box). While these countries have no prerequisites to enter vocational training, Dr Roberts-Thomson says that, in Australia, "there's an implicit understanding that you just need to do more research or more degrees".

Many doctors who spoke to the MJA question whether this extra research makes doctors better clinicians. One PGY2 doctor says the expectation for research is like asking a trainee mechanic to write a doctoral thesis on the life of Henry Ford before letting them change a tyre. "Being doctors, our duty is to manage patients, but there's this whole focus on getting papers, publishing research ... I feel there's too much emphasis on the icing and not enough on the cake itself", he says.

However, Dr Quinn points out that the application process for surgical training ascribes more "points" to the interview than to the CV. "You can spend years doing research, but that may not give you more points", he says.

Some vocational training programs also have clinical prerequisites, such as terms in intensive care. Dr Mitchell says it can be difficult for prevocational doctors to access these required terms - a situation that again may worsen with expanded student numbers.

\section{Improved efficiency}

Regardless of the value of the unaccredited years, many believe there needs to be improved coordination between the different stakeholders — such as universities, teaching hospitals and medical colleges - so doctors can progress more efficiently.

Health Workforce Australia (HWA), which was established by the Council of Australian Governments, aims to improve that coordination. HWA liaises with groups including specialty colleges, state and territory governments, and the Australian Medical Council. It has recently developed the first national workforce planning tool, Health workforce 2025, which projects the future supply of and demand for doctors, both geographically and by specialty, under different scenarios. At the time of writing, the plan was soon to be considered by the Australian health ministers.

HWA Chief Executive Officer Mark Cormack says it is important that the training system is informed by need, given the very long training times involved. "It's anticipated that these future projections will guide the pathways that doctors choose and also give some guidance to colleges and jurisdictions", he says.

"Provided that we can maintain the high quality of Australian doctors, I think most people would be keen to ensure that the training time is no longer than it needs to be."

Perhaps the most contentious issue is that of service registrar positions. Dr Mitchell says there is a need to determine if doctors who do unaccredited work could have this recognised to reduce the length of their accredited training, or whether some of these unaccredited positions could actually be accredited.

Other junior doctors argue that if there is capacity within the hospital system for unaccredited registrars, then surely the system could cope with additional accredited registrars.
However, Dr Quinn says it is not as easy as just accrediting the positions. "It's true that the hospital needs a certain workforce, but these are different types of jobs ... While the hospital might need people to do service jobs, they're not providing the level of training and exposure that is needed for accredited positions."

Dr Quinn says the RACS would like to train more surgeons, but there are not enough available accredited training positions - the numbers of which are determined
Being doctors, our duty is to manage patients, but there's this whole focus on getting papers, publishing research ... .

See MJA InSight for a comment piece by Professor David Tiller on the increasing length of training

MJA InSight www.mjainsight.com.au by state health departments. New South Wales Health says the mix of staff at each hospital is based on the services offered by the hospital and the optimum skill set required for these services.

\section{Time for a rethink?}

Others believe there should be an overhaul of the prevocational training system, although there is contention about striking the right balance between specialist and generalist training. Ideas include imposing a limit on the number of years doctors spend in unaccredited positions, or "streaming" doctors into specialty training earlier.

Dr Quinn says some aspects of generalist training, such as anatomy, need to be enhanced. He says streaming could offer a quicker training pathway for some doctors but might leave others "stuck"; for instance, if they've focused on surgical topics at medical school but are then unable to access surgical specialty training.

The view of the AMA Council of Doctors-in-Training is that trainees need a balanced and generalist approach at the start of their training, but should have the option of a vocational emphasis from their second postgraduate year.

Professor Celermajer believes trainee doctors should do a common medical degree of about 4 years, followed directly by specialist training, including the option for accelerated pathways. His latest dinner-party hypothetical is to ask colleagues how long they believe it should really take to train a doctor in their field.

"If you gave me a really bright 18-year-old and they followed me every day in an apprenticeship system, how long would it take me to make a good cardiologist out of them? I truly think the answer's about 5 years. Now that's radical - currently that process would take nearly 20 years — but I'm putting that out there."

\section{Competing interests: No relevant disclosures.}

All direct quotations and paraphrased comments are based on personal interviews.

1 Gerber JP, DeLoyde K. 2009 Commencing medical students questionnaire: national data report. Sydney: Medical Deans Australia and New Zealand, 2010. http://www.medicaldeans.org.au/wp-content/uploads/ 2009_CMSQ_report_2_pdf (accessed Apr 2012).

2 Australian Medical Association. Becoming a doctor and bonded medical student places - a guide for prospective medical students. Canberra: AMA, 2007. http://ama.com.au/node/4130 (accessed Apr 2012).

3 Royal Australian College of General Practitioners. The RACGP journey towards general practice. http:// www.racgp.org.au/Content/NavigationMenu/educationandtraining/Generalpracticecareer/pathwaytoGP_ flyer.pdf (accessed Apr 2012).

4 Medical Training Review Panel. Medical Training Review Panel fifteenth report. Canberra: Department of Health and Ageing, 2012. http://www.health.gov.au/internet/main/publishing.nsf/Content/5CEA280FF6 BD5659CA2579AE0000E151/\$File/MTRP15.pdf (accessed Apr 2012).

5 Woodward S. Med grads face no-man's land. Campus Review 2012; 19 Mar. http://www.campusreview. com.au/blog/international/med-grads-face-no-mans-land (accessed Apr 2012).

6 Royal Australasian College of Surgeons. Activities report for the period: 1 January - 31 December 2011. Melbourne: RACS, 2012. http://www.surgeons.org/media/465471/rpt2012-04-03_jan-dec_eoy_ar_final.pdf (accessed Apr 2012). 